that Basel Zoo has a captive population of 50 bald ibises? According to the International Zoo Yearbook they had 13. A statement on captive stocks, and their viability, for all other species being bred would have been useful.

My impression is that the publishers have imposed rigid restrictions of format which, while making the book attractive in appearance, have detracted from its ornithological value.

JOHN A. BURTON

Birds of the World: a check list, by James F. Clements. Two Continents Publishing Group, New York, \$15.

A Checklist of the Birds of the World, by Edward S. Gruson. Collins, $£ 3.95$. Birds: an illustrated survey of the bird families of the world, by John Gooders. Hamlyn, £6.95.

A complete check list of the birds of the world has been top of the list of ornithological desiderata for a very long time, in view of the fact that Peters's Birds of the World, started in the 1930s still lacks two volumes. Now, as so often happens, we have two plugs to fill the one gap. It is, of course, invaluable to have them; I only wish they had not both been so perversely pragmatic in their way of setting up the list. Just imagine setting out to create a list of birds of the world entirely from secondary sources, i.e. by consulting field guides and regional avifaunas. This is what both authors have done, Gruson more successfully than Clements. Inevitably there are shortcomings - Clements, for instance, has not picked up Pterodroma baraui, the new Réunion petrel. To my mind the only rational way of compiling a list of birds of the world is to start from Peters, and bring him up to date with the Zoological Record. Only with the tyrant flycatchers, the Old World warblers and the Old World flycatchers, occupants of Peters's missing volumes, should it be necessary to build up the list de novo from the literature.

Still, we should be thankful for what we have, however out-of-date some of their nomenclature - Gruson has not caught up with Phoebetria for two of the albatrosses, and neither author has achieved Calonectris in the shearwaters or Tachybaptus in the grebes. What is more, Clements caters for the classificatory heretics who like to put the crows near the beginning of the passerines, while Gruson sticks to Petersian orthodoxy and puts them at the end. It is a slight pity that we have two lists with so many differences in the order in which the families are listed.

These two books are for the specialist (who may nark a bit) and for the tick hunter. John Gooders has written a book of quite a different genre, one that will give the greatest pleasure to ordinary bird watchers, and comparable with Austin and Singer's and Gilliard's books on the birds of the world. Though it has been done before, its predecessors are mostly out of print, and it is useful to have it done again in this large volume of 350 pages, with good summaries of the characteristics of each bird family and over 400 excellent colour photographs.

RICHARD FITTER

\title{
The Identification of Mammalian Hair, by Hans Brunner and Brian Coman.
} Inkata Press, Melbourne £13.25.

This well produced book demonstrates a method of compiling a photographic index to hairs of a limited group of mammals. Unfortunately the title omits the essential information that it is designed primarily for ecologists working on the fauna of Victoria State, Australia.

The first eighteen pages include basic information on hair types, growth and the nomenclature for hair characters, the latter closely following Wildman (1954) with a few modifications. Descriptions of simple techniques and a system for the study of hairs are useful additions to this section and are of general interest. So 